Z. klin. Chem. u. klin. Biochem.

9. Jg., S. 396-397, September 1971

\title{
Ein Suchtest für Lipase im Serum
}

\author{
Von A. Härtel, D. Banauch und R. Helger \\ Biochemische Abteilung, E. Merck, Darmstadt
}

$\cdot$

(Eingegangen am 28. April 1971)

Es wird ein einfacher Test auf Lipase im Serum beschrieben. Als Substrat dient gereinigtes Olivenöl, gemesșen wird die durch die abgespaltenen Fettsäuren verursachte Farbänderung von $m$-Kresolpurpur. Der Test kann nach einstündiger Inkubation als Suchtest, oder nach zweistündiger Inkubation mit Hilfe eines Farbbandes halbquantitativ ausgewertet werden. Die Korrelation zur titrimetrischen Methode ist ausreichend. Die neue Methode wird für die Routinediagnostik empfohlen.

\section{A detection method for serum lipase}

A simple test for serum lipase is described. Purified olive oil is used as the substrate. $m$-Cresol purple is used as an indicator for the release of the free fatty acids. The test gives a qualitative result after 1 hour incubation, and it may be made semi-quantitative after two hours incubation. The results correlate satisfactorily with those from the titrimetric method. This new method is recommended for routine diagnosis.

Die Bedeutung der Lipase-Aktivität (EC 3.1.1.3) im Serum für die Diagnose von Pankreaserkrankungen ist in letzter Zeit mehrfach betont worden $(1,2,3)$. Trotzdem wird die Aktivität des Enzyms selten routinemäßig bestimmt, da die Methoden entweder apparativ aufwendig oder $\mathrm{zu}$ ungenau sind. Insbesondere wird durch das Substrat, eine Öl-in-Wasser-Emulsion, die direkte photometrische Messung erschwert. Man hat deshalb mehrfach versucht, andere leicht $\mathrm{zu}$ handhabende Substrate, wie z. B. Glycerinester von Fettsäuren niederer Kettenlänge, Nitrophenylester, Naphthylester, Polyäthylenglykolsorbitane, Trithioglycerintripalmitin und fluoresceinmarkiertes Olivenöl usw. zu verwenden. Alle diese Substrate werden jedoch auch durch die Esterasen des Serums gespalten. Für eine spezifische Bestimmung kommen nach den Arbeiten von RICK (4) nur Triolein und gereinigtes Olivenöl in Frage.

In dieser Mitteilung wird ein einfacher Test auf Lipase beschrieben, der ohne apparative Hilfsmittel durchgeführt wird. Es wird die durch Freisetzung der Fettsäuren verursachte $\mathrm{pH}-\mathrm{Verschiebung}$ mit Hilfe eines Farbindikators gemessen. Die Methode kann entweder als qualitativer Suchtest oder mit Hilfe einer Farbskala als halbquantitativer Test ausgewertet werden.

\section{Methode \\ Reagenzien}

Der Test wird mit Hilfe der Testpackung „Merckognost Lipase“ durchgeführt. Die Testpackung enthält eine gebrauchsfertige Olivenöl-Emulsion in einer Flasche mit Dosieraufsatz, Indikator, Testgefäße für den einmaligen Gebrauch, ein kalibriertes Farbband und Mischer. Die Emulsion enthält $150 \mathrm{ml}$ Olivenöl (gereinigt über Aktivkohle und basisches Aluminiumoxid) und $90 \mathrm{~g}$ gummi arabicum in $480 \mathrm{ml}$ Wasser und ist auf $\mathrm{pH} 7,0$ eingestellt. Zusatz von Calciumsalzen bzw. Desoxycholat ist in diesem Test nicht notwendig, da unter den Versuchsbedingungen durch diese Zusätze keine Steigerung der Nachweisempfindlichkeit bewirkt wird.

Der Indikator enthält $12,5 \mathrm{mg} m-\mathrm{Kresolpurpur} / \mathrm{ml} 0,05 \mathrm{~N} \mathrm{NaOH}$.

\section{Vorbereitung zum Test}

Man gießt die gesamte Indikatorlösung in die Emulsion und schüttelt, bis der Flascheninhalt homogen erscheint. Die Farbe der Emulsion ist ein braunstichiges Violett $=\mathrm{pH} \mathrm{8,6,} \mathrm{entsprechend}$ einem Farbton zwischen 0 und 60 auf der Farbskala. Wenn in seltenen Fällen der Farbton zu hell erscheint, wird mit wenigen Tropfen $0,1 \mathrm{~N} \mathrm{NaOH}$ nachgestellt. Ḍie gebrauchsfertige Emulsion ist bei $4^{\circ}$ mindestens 2 Wochen, bei $25^{\circ}$ mindestens eine Woche lang verwendbar; vor jedem Gebrauch muß jedoch geschüttelt werden.

\section{Test}

Mit Hilfe des Dosieraufsatzes werden je $2 \mathrm{ml}$ Emulsion in die Testgefäße abgefüllt; $0,2 \mathrm{ml}$ Serum werden zụpipettiert und mit dem Mischer gut durchmischt. Die Testgefäße läßt man bei Raumtemperatur stehen.

\section{Auswertung}

\section{Als Suchtest}

Nach 1 Std. Stehen werden die Testgefäße besichtigt. Seren mit stark erhöhten Lipase-Aktivitäten ergeben einen hellbraunen bis gelben Farbton und können von der Menge der normalen Seren (Farbton violett bis braun) gut differenziert werden.

\section{Halbquantitative Bestimmung}

Nach dem Mischen von Serum und Emulsion wird die Farbe der Emulsion mit dem Farbband verglichen und die entsprechende Zahl notiert. Nach einer halben Stunde bewertet man die Farbe der auffallend hellen Proben und nach weiteren $11 / 2 \mathrm{Stdn}$. die Farbe aller Proben. Die Differenz der Zahlen ergibt den Lipasegehalt in U/1. Hierbei muß man beachten, $\mathrm{da} B$ bei stark pathologischen Seren der Indikator nach 2 Stdn. Inkubation völlig umgeschlagen ist und nicht mehr mit der Farbskala differenziert werden kann. In diesen Fällen wird die nach einer halben Stunde vorgenommene Farbablesung ausgewertet und das Ergebnis mit 4 multipliziert. 

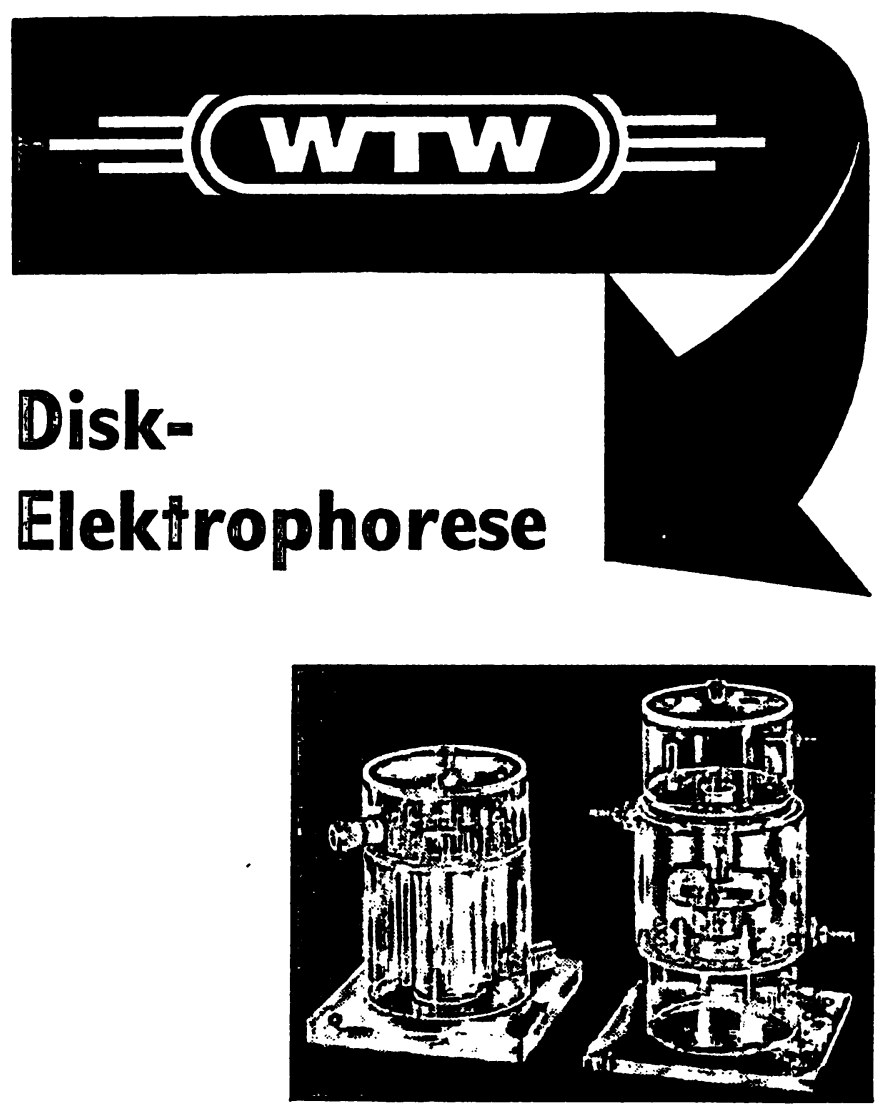

analytische Trennkammer EA 90 mit komplettem oder beliebigem Zubehör

\section{präparative Trennkammer EA 100}

mit synchroner Automatik bis zum Fraktionsteiler

\section{Densitometer PHI 3 und PHI 5}

für Elektrophorese und Chromatographie
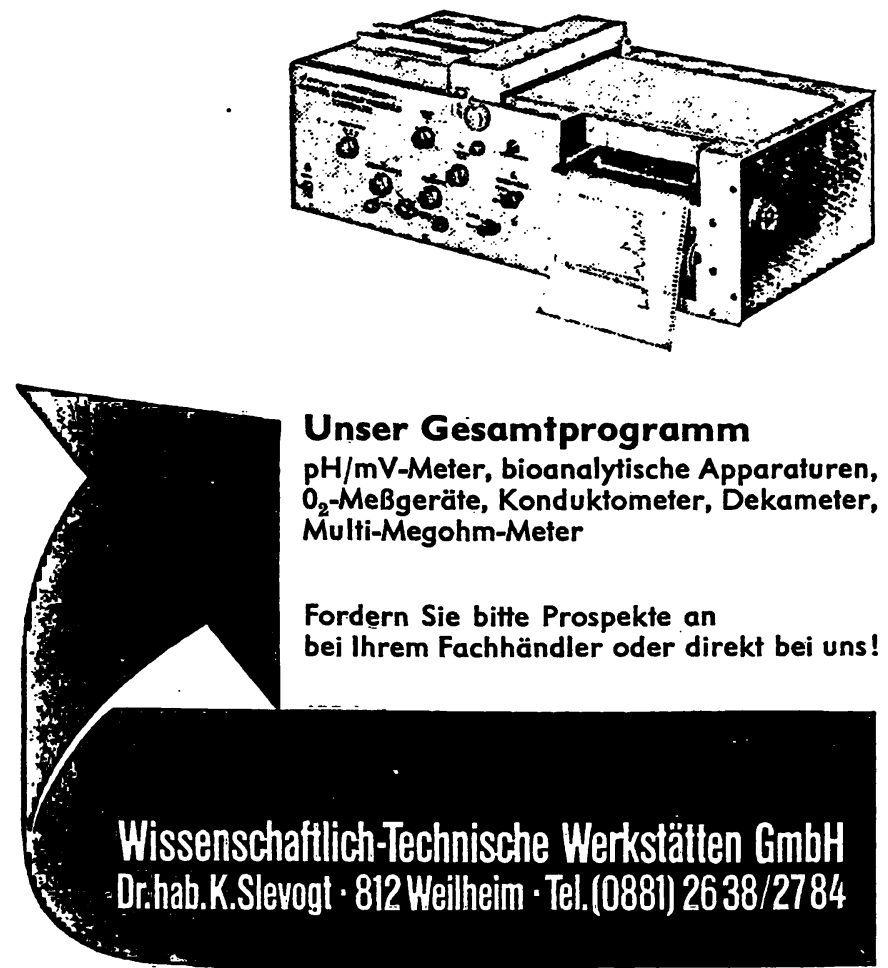

Büros: 43 Essen K. Akemann, Lönsberg 22, Ruf: (02141) 510029 7407 Dušslingen b. Tửbịngen W. Bohn, Farrenbergweg 5, Ruf: (07128) 7809

58 Hagen H. Duckstein, Hestertstr. 64, Ruf: (02331) 45857

635 Bad Nauheim H. Ballauff, Frankfurter Str. 39,

Ruf: (06032) 4860

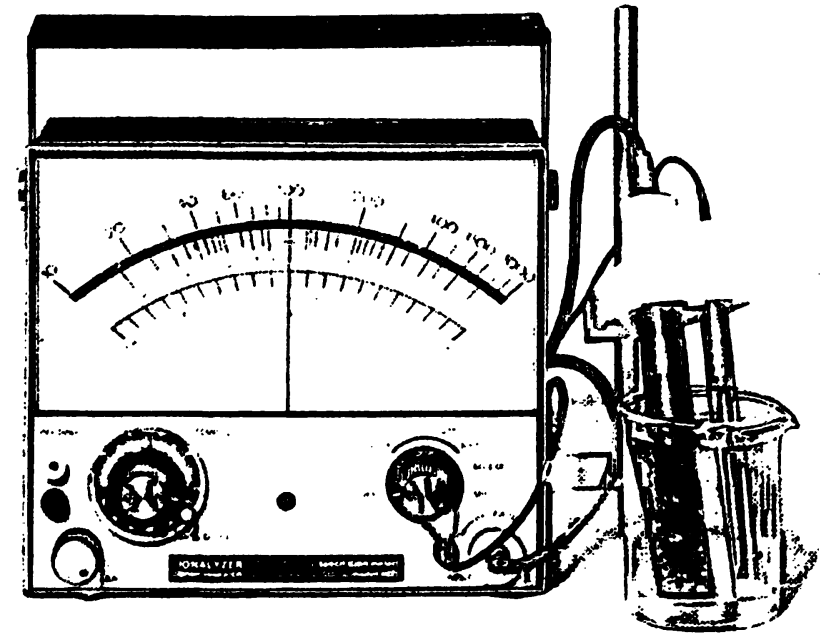

\section{Orion \\ Ionenselektive Elektroden}

Eine neue Technologie zur ionenselektiven Analyse flüssiger Medien. Die Analysensysteme bestehen aus speziellen Elektroden und elektronischen Digital- bzw. Analoggeräten. Es sind damit Einzel- und Simultanbestimmungen von z.B. $\mathrm{F}^{-}, \mathrm{Cl}^{-}, \mathrm{CN}^{-}$, $\mathrm{Na}^{+}, \mathrm{Ca}^{++}, \mathrm{Cu}^{++},\left(\mathrm{Ca}^{++}+\mathrm{Mg}^{++}\right)$ möglich. Das Verfahren ist leicht zu handhaben und methodisch erprobt.

Alleinvertretung für Deutschland:

\section{Colora Messtechnik GmbH}

7073 Lorch/Württ., Postfach 5 T (07172) 6041, FS 07-248886

Technische Büros (Verkauf und Kundendienst): 1000 Berlin 30, Kurfürstenstraße 84, T 135200 2000 Hamburg 19, Osterstraße 63, T 4006 06, FS 02-12947 3000 Hannover, An der Tiefenriede 45, T 884500 4000 Düsseldorf, Kronprinzenstr. 62, T 17860 , FS 08-587 253 6000 Frankfurta.M.,Röderbergweg 4-6,T446031, FS 04-11216 8000 München 2, Dachauer Straße 175, T 5169858

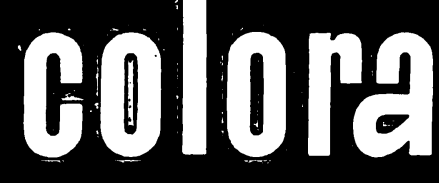




\section{Zur Beruhigung 国此res Gewissens:} HYLAND Richtigkeits-und Präzisionskontrollen.

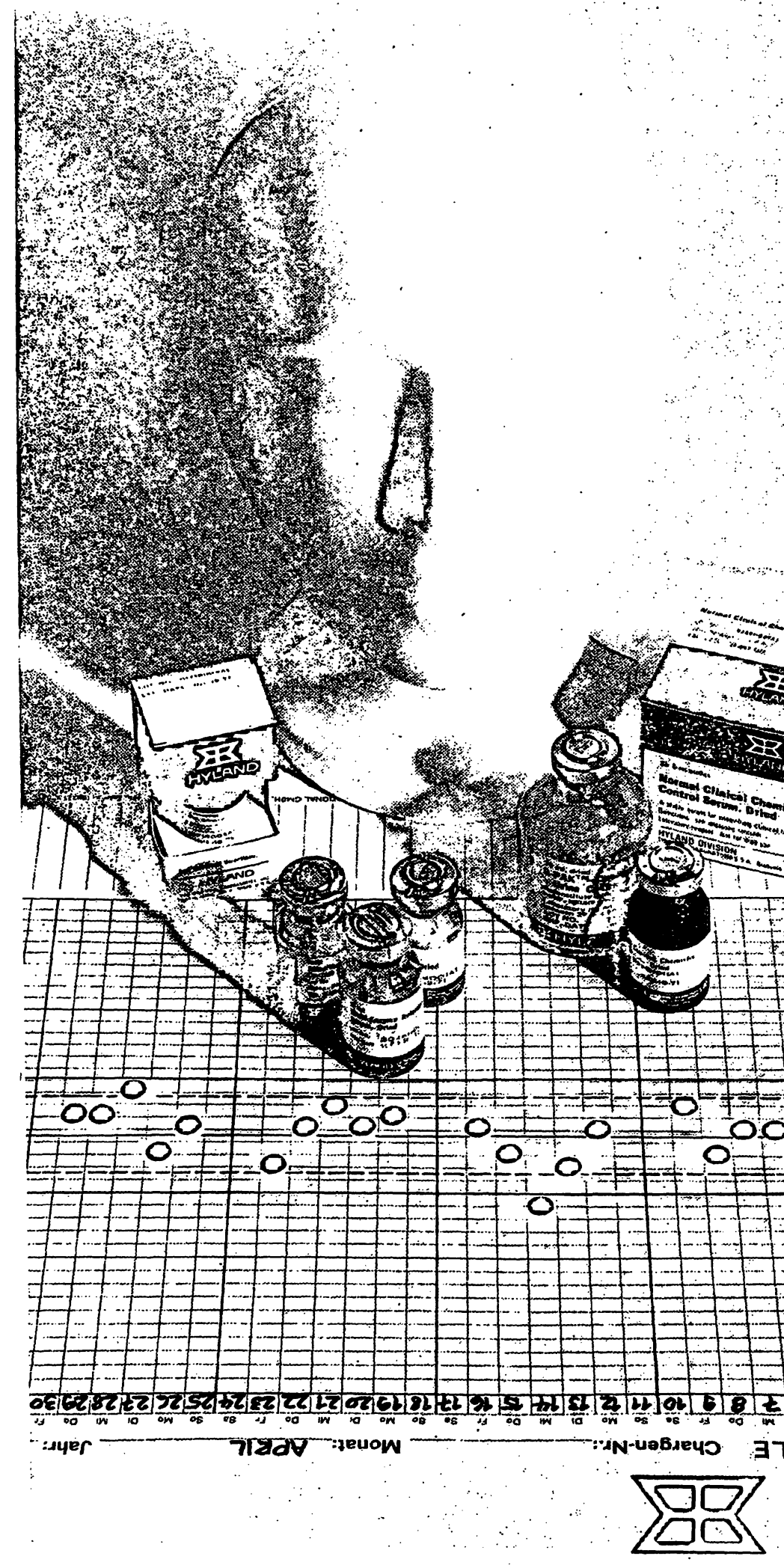

Präzisionskontrollen

Humanseren, Normal-Pathologisch Húmanserum „QPak" für Analyseautomaten Richtigkeitskontrollen

Humanseren, Normal"-Pathologisch"Spezial.

Humanserum ${ }_{n} \mathrm{OPak}$ für Analyseautomaten Multi-Enzym-Referenzserum

Bilirubinkontrolle mit erhöhten Werten Cholesterinkontrolle mit erhöhten Werten

Kontrollurine. Kontroll-Liquor $\mathrm{HB}$-Referenzstandard und-Kontrolle

Mit Europawerten

Mit HYLAND-Kontrollreagenzien können Sie mehr als 70 verschiedene Bestimmungen überprüfen.

Verlängen Sie bitte unsere Informationsunterlàgen. 


\section{Ergebnisse}

Die Abbildung 1 zeigt die Farbtöne verschiedener Serumproben mit unterschiedlicher Lipase-Aktivität nach 2 stdg. Laufzeit. Die Korrelation des Tests gegen die titrimetrische Methode nach RICK (2) ist in Abbildung 2 dargestellt. Die beim Suchtest auftretenden Abweichungen von $\leqq 60 \mathrm{U} / 1$ erscheinen im Hinblick auf die einfache Durchführung und die Möglichkeit, große Serien zu untersuchen, als tragbar. Der Test wurde von SchuLtis und Mitarbeitern in der Klinik in der Routinediagnostik überprüft. Die Ergebnisse dieser Prüfung sind an anderer Stelle publiziert worden $(1,5)$.

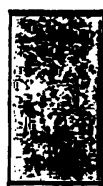

0

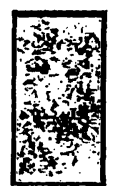

100

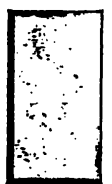

200

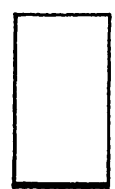

400 Lipase [U/I]

Abb. 1

Farbtönung von Tests mit Lipase-Aktivitäten von 0-1000 U/1 nach 2 Stdn.

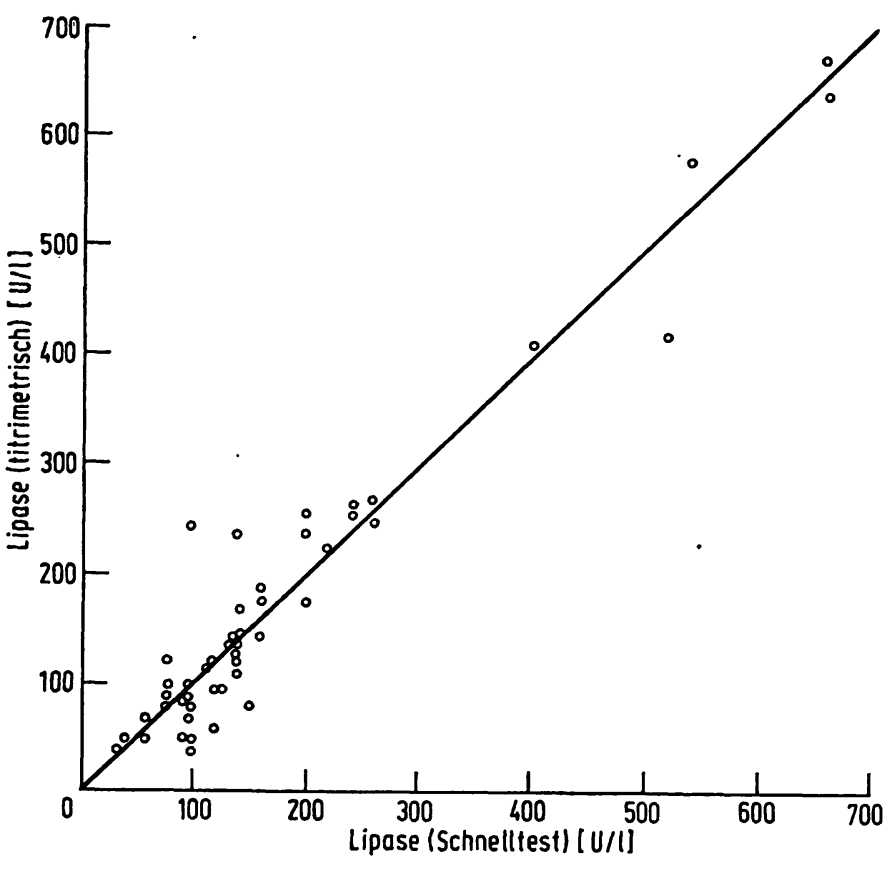

Abb. 2

Korrelation des Tests gegen die titrimetrische Methode nach RICK (2) $r=0,967$ $y=8,723+0,940 x$

\section{Literatur}

1. Schultis, K., E. WAGNer und E. Vossköhler, Schweiz. Med. Wschr. 99, 602 (1969). - 2. RIck, W. diese Z. 7, 530 (1969). 3. Gozbell, H., Internist 11, 117 (1970). - 4. Rrck, W., Internist
11, 110 (1970). - 5. VossKöhleR, E., Dissertation Univ. Gießen, 1970.

Dr. D. Banauch

Biochemische Abteilung

E. Merck

61 Darmstadt

Postfach 4119 